\title{
Inhibitory Activity of Levofloxacin against MDR Staphylococcus aureus and Pseudomonas aeruginosa Clinical
} Isolates

Lisa Nathalie ${ }^{1}$, Lindawati Alimsardjono $^{2}$, Isnaeni $^{1 *}$

${ }^{1}$ Departemen Kimia Farmasi, Fakultas Farmasi, Universitas Airlangga, Surabaya

${ }^{2}$ Departemen Mikrobiologi, Fakultas Kedokteran, Universitas Airlangga, Surabaya

*Corresponding Author: isnaeni@ff.unair.ac.id

Submitted: 29 April 2019

Accepted: 25 Juli 2019

Published online: 31 Juli 2019

\begin{abstract}
Introduction: Staphylococcus aureus and Pseudomonas aeruginosa are the most dangerous and important species among their genus. These bacteria are often resistant to many classes of antimicrobial agents; which make difficulties in selecting appropriate drug to treat infections. Multidrug-resistance occurs readily in hospitals for which antimicrobials agents were used widely. Objective: The aims of this study was to determine minimum inhibitory concentration (MIC) and minimum bacterial concentration (MBC) of levofloxacin against 22 multidrug resistant- clinical (MDR) strains of Staphylococcus aureus and Pseudomonas aeruginosa isolated from patients pus and urine in hospital. Methods: Determination of the MIC was performed by macro-dilution broth assay as recommended by Clinical and Laboratory Standards Institute (CLSI), while the MBC was determined one-step further after the MIC determination. Results: It was found that MIC of the levofloxacin were $(0.3 \pm 0.0)->0.5 \mu \mathrm{g} / \mathrm{mL}$ and $(0.2 \pm 0.1)-(1.0 \pm 0.0) \mu \mathrm{g} / \mathrm{mL}$ against $S$. aureus from pus and urine, respectively. In addition, higher MICs were yielded against P. aeruginosa, $(1.0 \pm 0.0)->8.0 \mu \mathrm{g} / \mathrm{mL}$ and $(0.7 \pm 0.3)-(3.0 \pm 1.2)$ $\mu \mathrm{g} / \mathrm{mL}$ for pus and urine isolates respectively. Similar to MICs, the MBCs against P. aeruginosa were higher than S. aureus, $(0.6 \pm 0.0)->4.0 \mu \mathrm{g} / \mathrm{mL}$ and $(0.3 \pm 0.0)->8.0 \mu \mathrm{g} / \mathrm{mL}$ isolated from pus and urine respectively, $(2.0 \pm$ 0.6) - > $8.0 \mu \mathrm{g} / \mathrm{mL}$ and $(3.0 \pm 1.2)->7.0 \mu \mathrm{g} / \mathrm{mL}$ against $P$. aeruginosa from pus and urine respectively. Conclusion: The levofloxacin was still susceptible as bacteriostatic against isolates from both body fluids, but not bactericidal towards all isolates.
\end{abstract}

Keywords: levofloxacin, MDR, Pseudomonas aeruginosa, Staphylococcus aureus

\section{INTRODUCTION}

Staphylococcus aureus and Pseudomonas aeruginosa are the most dangerous and important species among their genus (Forbes et. al., 2002; Kiska \& Gilligan, 2003). These bacteria are often resistant to enormous classes of antimicrobial agents; which make difficulties in selecting appropriate drug to treat infections (MacDougall et. al., 2005). Multidrugresistance occurs readily in hospitals as a place where antimicrobial used widely. Susceptibility test in pus and urine isolates at Dr. Soetomo General Hospital Surabaya (DSGHS) from August 2005 to February 2006 showed that $74.1 \%$ of $S$. aureus isolates $(\mathrm{n}=85)$ and $95.9 \% \quad P$. aeruginosa isolates $(\mathrm{n}=222)$ were
MDR-isolates. The MDR is defined as resistance against at least two antimicrobial agents from different class.

Fluoroquinolone is derived from quinolone contains fluorin on the sixth carbon atom (C-6) of quinolone structure (Yao \& Moellering, 2003). The fluoroquinolone is widely used and prescribed for more than $11 \%$ (Gilbert, 2001). Levofloxacin, one of quinolone new generation and an optical isomer of ofloxacin is widely used in clinical practice due to safety and efficacy. The antibiotic is also known to have highly effectiveness against $S$. aureus and less likely to cause resistance compared to older quinolones (Evans \& Titlow, 1998). Study on 
evaluation of the utility of various commonly used fluoroquinolones against 250 clinical isolates of $S$. aureus showed that among the fluoroquinolones, maximum resistance in methicillin-resistant $S$. aureus (MRSA). There was seen to ciprofloxacin (92.5\%), followed by ofloxacin $(80.4 \%)$, no reports on the levofloxacin (Gade and Oazi, 2013). Muller et. al. (1999) proved the superior activity of levofloxacin over that of ofloxacin against methicillin-susceptible $S$. aureus (MSSA) and methicillin-resistant S. aureus (MRSA).

Disk diffusion test of levofloxacin against $S$. aureus and $P$. aeruginosa isolates from pus and urine in DSGHS for 7 months (August 2005 to February 2006) indicated that $1.56 \%(\mathrm{n}=64)$ S. aureus and $42.76 \%(\mathrm{n}=145) P$. aeruginosa isolates were resistant against this drug. In this research, the MIC and MBC of levofloxacin against MDR-isolates of $S$. aureus and $P$. aeruginosa were studied to be aware of possible changes in levofloxacin activity since sensitivity test has not been done after February 2006. The isolates were hypothesized susceptible against levofloxacin.

\section{MATERIAL AND METHODS}

\section{Materials}

Levofloxacin was synthesized in Daiichi Pharmaceutical Co., Ltd. (Tokyo, Japan). Stock solution of levofloxacin was prepared at concentration of $100 \mu \mathrm{g} / \mathrm{mL}$, and dissolved in sterile water. This solution was diluted in sterile water to achieve 0.125 , $0.25,0.5,1,2,4$, and $8 \mu \mathrm{g} / \mathrm{mL}$ of the antimicrobial solution.

Staphylococcus aureus ATCC 25923 and Pseudomonas aeruginosa ATCC 27853 were used as standard strains. Isolate of bacterial test were obtained from pus and urine in DSGHS. Selected strains for the MIC and MBC determination should meet the criteria of being resistant toward minimal two antimicrobial agents from different classes. The sample size was determined using Stein's-Two Stage Sample, yielding 11 isolates of $S$. aureus and P. aeruginosa, each (Ostle \& Mensing, 1975; Steel \& Torrie, 1981). Müller Hinton Broth (MHB, Oxoid, England) was used as the test medium for MIC determination and nutrient agar (Oxoid, England) was used as medium for inoculum preparation and $\mathrm{MBC}$ determination.

\section{Methods}

\section{Sample colletion}

Samples were obtained from pus and urine patients from DSGHS identified as MDR strains based on retrospective study. The number of test samples was calculated based on Stein's Two-Stage Sample method, in which the determination of the minimum inhibitory levels of several isolates, calculated the average value and standard deviation of each isolate, then the remaining isolates were determined by matching the $\mathrm{D}$ value, the comparison between the results experiments with results that were considered to have a significant effect $(\delta)$ with a standard deviation $(\sigma)$ at the level of $\alpha$ (significance or probability of making type I errors) and $\beta$ (probability of making type II errors) that have been determined at the beginning of the study (Ostle \& Mensing, 1975; Steel \& Torrie, 1981). This study used a value of $\alpha=0.05$ and $\beta=0.10$.

\section{Inoculum preparation}

Cultures of $S$. aureus and $P$. aeruginosawere grown on non-selective media (nutrient agar) and incubated overnight. A total of 4 - 5 colonies were taken with Öse needle then made suspensions in MHB media. Turbidity level was adjusted with 0.5 McFarland solutions by adding liquid media or adding bacterial colonies (Jorgensen \& Turnidge, 2003).

\section{Minimum inhibitory concentration (MIC) Determination}

The MIC was determined by the macro dilution assay in Müller Hinton Broth. Direct colony suspension method was used for inoculum preparation using nutrient agar as a medium. The macro dilution assays were performed using ten sterile 16 x 100-mm test tubes containing serial twofold dilutions of each diluted antimicrobial agent. The final inoculum prepared from logarithmic-phase bacteria was $5 \mathrm{x} 103$ $\mathrm{CFU} / \mathrm{mL}$. The MIC was defined as the lowest concentration of antimicrobial agent which completely inhibited visible bacterial growth in the tubes as detected by unaided eyes (CLSI, 2006).

\section{Minimum bacterial concentration (MBC) determination}

Determining MICs was followed by MBC determination. An aliquot from each tube in the dilution series exhibited bacterial inhibition was subcultured into nutrient agar. After an overnight incubation (18 - 20 hours), the colonies on plates were counted. The MBC is defined as the lowest antimicrobial concentration which inhibits $99.9 \%$ bacterial growth compared to bacterial concentration in the original inoculum. Forbes et. al. (2002) defined the MBC as the antimicrobial concentration inhibits $100 \%$ bacterial growth on the plate. 


\section{Analysis of data}

The MIC and MBC values of each strain were determined based on the serial dilution (Figure 1) method. The observation results were used to determine levofloxacin activity profiles against these two bacteria. These values were determined thrice and the mean values were determined as the MIC or MBC. The lowest concentration of levofloxacin which completely inhibited visible bacterial growth in the tubes as detected by visible observation denoted as
MIC. The inhibitory concentration by which $100 \%$ of bacterial growth on the plate was inhibited denoted as MBC.

In vitro resistance of $S$. aureus toward levofloxacin is defined as $\mathrm{MIC} \geq 4 \mu \mathrm{g} / \mathrm{mL}, \mathrm{MIC}=2 \mu \mathrm{g} / \mathrm{mL}$ for intermediate, and $\mathrm{MIC} \leq 1 \mu \mathrm{g} / \mathrm{mL}$ for susceptibility border. Whilst resistance of $P$. aeruginosa to levofloxacin is defined as MIC of $\geq 8 \mu \mathrm{g} / \mathrm{mL}, \mathrm{MIC}=4$ $\mu \mathrm{g} / \mathrm{mL}$ for intermediate, and $\mathrm{MIC} \leq 2 \mu \mathrm{g} / \mathrm{mL}$ for susceptibility border (CLSI, 2006).

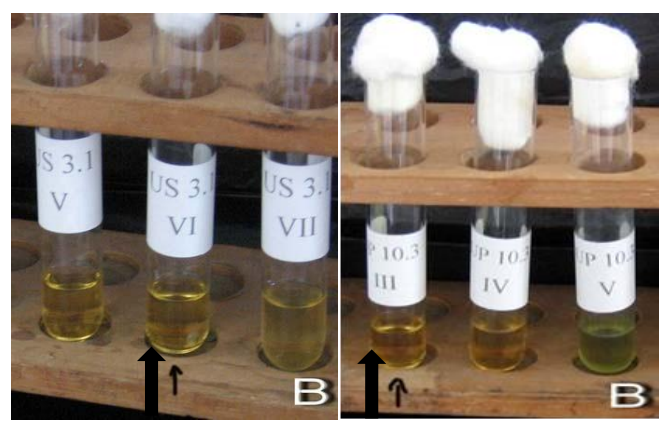

Figure 1. Observation of MIC $(\rightarrow)$ using serial dilution test $\mathrm{S}=$ Staphylococcus aureus, $\mathrm{P}=$ Pseudomonas aeruginosa

\section{RESULTS AND DISCUSSION}

The disk diffusion susceptibility test performed towards 22 selected isolates used in this study. Wholly $S$. aureus showed methicillin-susceptible $S$. aureus (MSSA). All isolates from both body fluid showed resistance against more than two antibiotics classes (Table 1 and Table 2).

Table 1. In vitro activity of levofloxacin against Staphylococcus aureus pus isolates (Retrospective study)

\begin{tabular}{lll}
\hline Isolate Code & Resistant & Susceptible \\
\hline SP 1 & PEN, CHL & MET, NVB, SXT, GEN, NET, VAN, NIT, FOF, \\
SP 2 & CLI, ERY, CFP-SUL, TET \\
& PEN, ERY, CLI, TET & MET, NVB, CHL, NIT, GEN, FOF, CFP-SUL, \\
SP 3 & GAT, VAN, NET \\
& PEN, TET & MET, NVB, CLI, SXT, ERY, GEN, CFP-SUL, \\
SP 4 & VAN, CHL, FOF \\
& PEN, NIT ${ }^{a}$ & MET, NVB, FOF, NET, GEN, VAN, CHL, SXT, \\
SP 5 & CLI, TET, CFP-SUL, ERY \\
& PEN, TET & MET, NVB, NIT, VAN, CFP-SUL, SXT, FOF, \\
SP 6 & ERY, NET, CLI \\
& MET, NVB, CHL, SXT, FOF, GEN, ERY, VAN, \\
SP 7 & PEN, SXT, CHL, ERY, NIT (I) ${ }^{a}$ & MET, NFP-SUL, CLI, NIT, NET \\
\hline
\end{tabular}

${ }^{a}$ : intermediate, SP: S. aureus collected from pus

Table 2. In vitro activity of levofloxacin against Staphylococcus aureus urine isolates (Retrospective study)

\begin{tabular}{lll}
\hline Isolate Code & Resistant & Susceptible \\
\hline SU 1 & PEN, TET & MET, NVB, ERY, SXT, VAN, GAT, NIT, CHL, \\
& NET, MEM, GEN, FOF, CFP-SUL, CLI \\
SU 2 & PEN, ERY & MET, NVB, NET, NIT, CFP-SUL, GAT, FOF, \\
& & GEN, CLI, VAN, SXT, TET, CHL \\
SU 3 & PEN, CHL $^{a}, \mathrm{NET}^{a}, \mathrm{GEN}, \mathrm{TET}, \mathrm{CLI}^{a}$ & MET, NVB, ERY, VAN, NIT, GAT, FOF, CFP- \\
& SUL & MET, NVB, VAN, TET, FOF, NIT, ERY, CHL, \\
\hline
\end{tabular}

SU: S. aureus collected from urine 
The susceptibility test has not been conducted by levofloxacin since February 2006. The levofloxacin activity assay was performed by using MIC and MBC parameters. The MIC of levofloxacin against $S$. aureus isolated from pus $(0.3 \pm 0.0)->0.5 \mu \mathrm{g} / \mathrm{mL}$ showed less susceptible compare to urine isolates $(0.2$ $\pm 0.1)-(1.0 \pm 0.0) \mu \mathrm{g} / \mathrm{mL}$ (Table 3$)$. The five of seven pus isolates (bacterial isolated from pus) (71.4\%) and all four urine isolates are susceptible (Table 4).

Table 3. In vitro activity of levofloxacin against Pseudomonas aeruginosa pus isolates (Retrospective study)

\begin{tabular}{lll}
\hline Isolate Code & Resistant & Susceptible \\
\hline PP 1 & AMK (I), NET, CIP, SXT, CTX, AMP, & CAZ, CFP-SUL, MEM, FEP, FOF, TZP, ATM \\
& GAT, GEN, AMC & \\
PP 2 & GEN (I), SXT, AMC, AMP & GAT, FEP, TZP, ATM, NET, CIP, CFP-SUL, \\
PP 3 & FMP, FOF (I), AMC, SXT & FOF, CTX, CAZ, AMK, MEM \\
& & AMK, CIP, TZP \\
PP 4 & AMC, AMP, SXT, CTX (I) & FOF, CFP-SUL, NET, CAZ, FEP, TZP, MEM, \\
& FOF, SXT, AMC, CTX & CIP, ATM, GEN, GAT, AMK \\
PP 5 & CFP-SUL, CIP, TZP, NET, CFP-SUL, C, GEN, \\
& FOF (I), AMP, AMC, SXT & DA, SXT, VAN, ERY \\
PP 6 & MEM, CIP, CTX, FEP, TZP, ATM, AMK, NET, \\
& AMC, AMP, SXT & GEN, CAZ, CFP-SUL \\
PP 7 & CFP-SUL, AMK, MEM, FEP, GAT, FOF, CIP, \\
& NET, CAZ, TZP, CTX, GEN, ATM \\
\hline
\end{tabular}

$\overline{\mathrm{PP}}=P$. aeruginosa collected from pus

Table 4. In vitro activity of levofloxacin against Pseudomonas aeruginosa urine isolates (Retrospective study)

\begin{tabular}{lll}
\hline Isolate Code & Resistant & Susceptible \\
\hline PU 1 & SXT, AMC & CAZ, AMK, TZP, ATM, CFP-SUL, FOF, MEM, \\
& & NET, GEN, CIP, FEP, CTX, \\
PU 2 & AMC, SXT, CTX (I) & ATM, FEP, MEM, CAZ, GEN, AMK, GAT, \\
& & TZP, CFP-SUL, FOF, NET, CIP \\
PU 3 & AMC, CTX(I), SXT, FOF (I) & CAZ, GAT, CFP-SUL, ATM, AMK, TZP, FEP, \\
& & NET, GEN, CIP, MEM \\
PU 4 & SXT, AMC, CTX & CAZ, NET, ATM, GEN, MEM, FEP, AMK, CIP, \\
& & TZP, FOF, CFP-SUL \\
\hline
\end{tabular}

$\mathrm{PU}=P$. aeruginosa collected from urine

AMK: Amikacin; AMC: Amoxicilin-clavulanic acid; AML: Ampicillin; ATM: Aztreonam;

C: chloramphenicol; CAZ: ceftazidime; CIP: ciprofloxacin; GEN: Gentamicin; CTX: cefotaxime;

CXM: cefuroxime; DA: Clindamycin; F: Nitrofurantoin; FEP: Cefepime; FOF: Fosfomycin;

GAT: Gatifloxacin; LEV: Levofloxacin; MEM: meropenem; MET: methicillin; NET: Netilmicin;

NV: novobiocin; P: Penicillin; CFP-SUL: cefoperazone-sulbactam; SXT: cotrimoxazole; TE: tetracycline;

TZP: piperacillin-tazobactam; VAN: vancomysin; ERY: erythromycin

The MBC values against pus isolates against $S$. aureus $(2.0 \pm 0.6)->8.0 \mu \mathrm{g} / \mathrm{mL}$ were also lower than MBC against urine isolates, $(3.0 \pm 1.2)->7.0 \mu \mathrm{g} / \mathrm{mL}$ (Table 5 and Table 6). Research done by Muller et. al. (1999) on the serum bactericidal activity (SBA) of levofloxacin used 10 healthy volunteers collected after a single oral dose of either levofloxacin $(500 \mathrm{mg}$ ) or ofloxacin (400 mg) indicated that the levofloxacin was significantly more bactericidal than ofloxacin against all strains of $S$. aureus tested. 
Table 5. In vitro MIC and MBC of levofloxacin against Staphylococcus aureus pus isolates

\begin{tabular}{ccccc}
\hline Isolate Code & $\begin{array}{c}\text { MIC } \pm \text { SD } \\
(\mu \mathrm{g} / \mathrm{mL})\end{array}$ & $\begin{array}{c}\text { MBC } \pm \mathrm{SD} \\
(\mu \mathrm{g} / \mathrm{mL})\end{array}$ & $\begin{array}{c}\text { MBC/MIC } \\
\text { ratio }\end{array}$ & Note \\
\hline Standard strain & $2.0 \pm 0.0$ & $>7.0$ & $>3.5$ & Not bactericidal \\
\hline SP 1 & $0.3 \pm 0.0$ & $0.6 \pm 0.0$ & 2 & Bactericidal \\
SP 2 & $1.0 \pm 0.8$ & $2.0 \pm 0.9$ & 2 & Bactericidal \\
SP 3 & $1.0 \pm 0.6$ & $>4.0$ & $>4$ & Not Bactericidal \\
SP 4 & $>0.5$ & $>1.0$ & $>2$ & Not Bactericidal \\
SP 5 & $0.5 \pm 0.0$ & $1.0 \pm 0.6$ & 2 & Bactericidal \\
SP 6 & $0.5 \pm 0.0$ & $4.0 \pm 3.5$ & 8 & Not Bactericidal \\
SP 7 & $3.3 \pm 1.2$ & $3.0 \pm 1.2$ & 0.9 & Bactericidal \\
\hline
\end{tabular}

Table 6. In vitro MIC and MBC of levofloxacin against Staphylococcus aureus urine isolates

\begin{tabular}{ccccc}
\hline Isolate Code & $\begin{array}{c}\text { MIC } \pm \text { SD } \\
(\mu \mathrm{g} / \mathrm{mL})\end{array}$ & $\begin{array}{c}\mathrm{MBC} \pm \mathrm{SD} \\
(\mu \mathrm{g} / \mathrm{mL})\end{array}$ & $\begin{array}{c}\mathrm{MBC} / \mathrm{MIC} \\
\text { ratio }\end{array}$ & Note \\
\hline Standard strain & $2.0 \pm 0.0$ & $>7.0$ & $>3.5$ & Not bactericidal \\
\hline SU 1 & $0.2 \pm 0.1$ & $0.3 \pm 0.0$ & 1.5 & Bactericidal \\
SU 2 & $0.3 \pm 0.0$ & $>8.0$ & 26.7 & Not Bactericidal \\
SU 3 & $0.7 \pm 0.3$ & $0.8 \pm 0.3$ & 1.1 & Bactericidal \\
SU 4 & $1.0 \pm 0.0$ & $>8.0$ & $>8$ & Not Bactericidal \\
\hline
\end{tabular}

Based on the data analysis, it could be concluded that in vitro susceptibility of $S$. aureus against levofloxacin was better than $P$. aeruginosa. Higher MICs were yielded against $P$. aeruginosa, $(1.0 \pm 0.0)$ $>8.0 \mu \mathrm{g} / \mathrm{mL}$ and $(0.7 \pm 0.3)-(3.0 \pm 1.2) \mu \mathrm{g} / \mathrm{mL}$ for pus and urine isolates respectively. Similar to MICs, the MBCs against $P$. aeruginosa were higher than $S$. aureus, $(0.6 \pm 0.0)->4.0 \mu \mathrm{g} / \mathrm{mL}$ and $(0.3 \pm 0.0)->$ $8.0 \mu \mathrm{g} / \mathrm{mL}$ isolated from pus and urine respectively, $(2.0 \pm 0.6)->8.0 \mu \mathrm{g} / \mathrm{mL}$ and $(3.0 \pm 1.2)->7.0 \mu \mathrm{g} / \mathrm{mL}$ against $P$. aeruginosa from pus and urine respectively (Table 7 and Table 8). Similar results were obtained in other research (Drago, 2001). It was found that levofloxacin was active, defined as having ability to be a bacteriostatic and bactericidal agent against MDR isolates. Nester et. al. stated that antimicrobial agent is considered bactericidal if MBC is 2 - 4 times than MIC (Nester et. al., 1973). Another statement concluded that levofloxacin was considered as bactericidal when its $\mathrm{MBC}$ is equal or slightly higher than MIC (JanssenOrtho, 2005). Basis on those secondary evidences could be considered that levofloxacin as a bactericide on behalf $\mathrm{MBC} / \mathrm{MIC}$ rate was $\geq 4$.

Table 7. In vitro MIC and MBC of levofloxacin against Pseudomonas aeruginosa pus isolates

\begin{tabular}{ccccc}
\hline Isolate Code & $\begin{array}{c}\mathrm{MIC} \pm \mathrm{SD} \\
(\mu \mathrm{g} / \mathrm{mL})\end{array}$ & $\begin{array}{c}\mathrm{MBC} \pm \mathrm{SD} \\
(\mu \mathrm{g} / \mathrm{mL})\end{array}$ & $\begin{array}{c}\mathrm{MBC} / \mathrm{MIC} \\
\text { ratio }\end{array}$ & Note \\
\hline Standard strain & $2.0 \pm 0.0$ & $>7.0$ & $>3.5$ & Not bactericidal \\
\hline PP 1 & $>8.0$ & $>8.0$ & $>1$ & Not Bactericidal \\
PP 2 & $1.7 \pm 0.6$ & $4.7 \pm 3.1$ & 2.8 & Bactericidal \\
PP 3 & $1.7 \pm 0.6$ & $3.0 \pm 1.2$ & 1.8 & Bactericidal \\
PP 4 & $1.0 \pm 0.6$ & $3.0 \pm 1.2$ & 3 & Bactericidal \\
PP 5 & $1.0 \pm 0.0$ & $2.0 \pm 0.6$ & 2 & Bactericidal \\
PP 6 & $1.0 \pm 0.6$ & $>4.0$ & $>4$ & Not Bactericidal \\
PP 7 & $3.0 \pm 1.2$ & $8.0 \pm 0.0$ & 2.7 & Bactericidal \\
\hline
\end{tabular}

Table 8. In vitro MIC and MBC of levofloxacin against Pseudomonas aeruginosa urine isolates

\begin{tabular}{ccccc}
\hline Isolate Code & $\begin{array}{c}\text { MIC } \pm \text { SD } \\
(\mu \mathrm{g} / \mathrm{mL})\end{array}$ & $\begin{array}{c}\mathrm{MBC} \pm \mathrm{SD} \\
(\mu \mathrm{g} / \mathrm{mL})\end{array}$ & $\begin{array}{c}\text { MBC/MIC } \\
\text { ratio }\end{array}$ & Note \\
\hline Standard strain & $2.0 \pm 0.0$ & $>7.0$ & $>3.5$ & Not bactericidal \\
\hline PU 1 & $0.7 \pm 0.3$ & $>5.0$ & $>7.1$ & Not Bactericidal \\
PU 2 & $0.8 \pm 0.3$ & $3.0 \pm 1.2$ & 3.8 & Bactericidal \\
PU 3 & $3.0 \pm 1.2$ & $3.0 \pm 1.2$ & 1 & Bactericidal \\
PU 4 & $3.0 \pm 1.2$ & $>7.0$ & $>2.3$ & Not Bactericidal \\
\hline
\end{tabular}


Several factors affected antimicrobial activity in vitro, such as $\mathrm{pH}$, inoculum size, incubation time, drug susceptibility, patient's condition as a source of the test bacteria, antimicrobial and bacteria characteristic (Koneman et. al., 1997; Brooks et. al., 2001). Inoculum size used in this research $(106 \mathrm{CFU} / \mathrm{mL})$ was lower than usual colony in infected tissue (108-1010CFU/g), might cause decreased of antimicrobial activity in vivo, but according to Mizunaga et. al. (2005), decreasing fluoroquinolone activity was not well-correlated with high inoculum size, but depends on the antimicrobial and bacteria characteristic. Larger incubation time might be bias the result because as incubation time increase, antimicrobial concentration is decrease. The incubation time was ranged 18 - 20 hours to avoid this problem.

$S$. aureus susceptibility against levofloxacin was higher than $P$. aeruginosa, because there was a substitution in C-7 position with pyrrolidinyl moiety; which enhances quinolones activity against Grampositives bacterias (Bambeke et. al., 2003; Mitscher, 2005). There was also a concern of additional mechanism of levofloxacin against Gram-positive bacteria, which are active on non-dividing cells and not requiring protein or RNA synthesis (Montanari et. al., 1999). Various efflux pumps of $P$. aeruginosa also lead to more MDR compare with $S$. aureus because various efflux pumps enable substrates to attach on and finally increase drug resistance (Bambeke et. al., 2003).

There are also differences in fluoroquinolone activities against several pathogenic bacteria as proved previously by Mitscher (2005). Those differences may also be seen in our sample SP 2; which was in intermediate border against levofloxacin but susceptible against gatifloxacin. Pseudomonal isolates, PP 7 and PU 3 were also in intermediate level against levofloxacin, but susceptible against gatifloxacin and ciprofloxacin.

Commonly, a resistance in single antimicrobial agent will give similar result to the rest agents in the same class (Heritage, 2001; Muramatsu et. al. 2005). On the other side, Cunha (2001) argued that old generation of quinolones (nalidixic acid, norfloxacin) and ciprofloxacin are highly potential to cause resistance and their limitation use in clinical practice will reduce resistance against quinolones. Nevertheless, we suggest that alternative agent against levofloxacin resistant isolate is better be chosen from different antimicrobial class.
In conclusion, levofloxacin has still active as a bacteriostatic and bactericidal activity against MDR-S. aureus and $P$. aeruginosa clinical isolates, however further studies on this subject are warranted using larger sample size and well-correlated with in vivo condition.

\section{CONCLUSION}

The Levofloxacin was still active as a bacteriostatic and bactericidal activity against MDR $S$. aureus and $P$. aeruginosa clinical isolates, but further studies on this subject are warranted using larger sample size and well-correlated with in vivo condition.

\section{ACKNOWLEDGMENTS}

We express our thanks to Daiichi Pharmaceutical Co., Ltd for supplying levofloxacin, James $H$. Jorgensen and Jennifer M. Andrews for valuable document and suggestions.

\section{REFERENCES}

Bambeke, F. V., Gllupeczynski, Y., Plésiat, P., Pechère, J. C. \& Tulkens, P. M. (2003). Antibiotic Efflux Pumps in Procaryotic Cells: Occurrence, Impact on Resistance and Strategies for the Future of Antimicrobial Therapy. Journal of Antimicrobial Chemotherapy; 51; 1055-1065.

Brooks, G. F., Butel, J. S. \& Morse, S. A. (2001). Jawetz, Melnick and Adelberg's Medical Microbiology. 22th ed. Boston: Appleton \& Lange.

Clinical and Laboratory Standards Institute. (2006). Methods for Dilution Antimicrobial Susceptibility Test for Bacteria that Grow Aerobically - Seventh Edition; Approved standard M7-A7. Wayne, PA: CLSI.

Clinical and Laboratory Standards Institute. (2006). Performance Standards for Antimicrobial Susceptibility Testing: Sixteenth Informational Supplement M100-S16. Wayne, PA: CLSI.

Cunha, B. A. (2001). Effective Antibiotic-Resistance Control Strategies. Lancet; 3537; 1307-1308.

Drago, L., De Vecchi, E., Mombelli, B., Nicola, L., Valli, M. \& Gismondo, M. R. (2001). Activity of Levofloxacin and Ciprofloxacin against Urinary pathogens. Journal of Antimicrobial Chemotherapy; 48; 37-45.

Evans, M. E. \& Titlow, W. B. (1998). Levofloxacin Selects Fluoroquinolone-resistant Methicillin- 
Resistant Staphylococcus aureus Less Frequently than Ciprofloxacin. Journal of Antimicrobial Chemotherapy; 41; 285-288.

Forbes, B. A., Sahm, D. F. \& Weissefeld, A. S. (2002). Bailey and Scott's Diagnostic of Microbiology, $11^{\text {th }}$ ed. St. Louis: Mosby-Year Book, Inc.

Gade, N. D., Oasi, M. S. (2013). Fluoroquinolone Therapy in Staphylococcus aureus Infections: Where Do We Stand?. Journal of Laboratory Physicians; 5; 109-112.

Gilbert, D. N., Kohlhepp, S. J., Slama, K. A., Grunkemeier, G., Lewis, G., Dworkin, R. J., Slaughter, S .E. \& Leggett, J. E. (2001). Phenotypic Resistance of Staphylococcus aureus, Selected Enterobacteriaceae, and Pseudomonas aeruginosa after Single and Multiple In Vitro Exposures to Ciprofloxacin, Levofloxacin, and Trovafloxacin. Antimicrobial Agents and Chemotherapy; 45; 883-892.

Muller-Serieys, C., Decré, D., Benoit, C., Bigot, C., Maubert, B., Carbon, C. (1999). Levofloxacin: Serum Bactericidal Activity against MethicillinResistant Staphylococcus aureus isolates. Journal of Antimicrobial Chemotherapy; 43; 6770.

Heritage, J., Wilcox, M. \& Sandoe, J. (2001). Antimicrobial Resistance Potential. Lancet; 358; 1099-1100.

Janssen-Ortho, Inc. 2005. Levaquin by Jansen-Otrho. http://www.orthomcneil.com/.../assets/common/ company/pi/levaquin.pdf;jsessionid=CWW2VR 14AOBGWCQPCCEDCOYKB2IIWNSC.

Accessed: 25 Juli 2006.

Jorgensen, J. A. \& Turnidge, J. D. (2003). Susceptibility Test Methods: Dilution and Disk Diffusion Methods. USA: WMC Brown Publishers.

Kiska, D. L. \& Gilligan, P. H. (2003). Manual of Clinical Microbiology ( $8^{\text {th }}$ ed). Washington, DC: ASM Press,.

Koneman, E. W., Allen, S. D., Janda, W. M., Schreckenberger, P. C. \& Winn, Jr., W. C.
(1997). Color Atlas and Textbook of Diagnostic Microbiology ( $5^{\text {th }}$ ed). St. Louis: Mosby, Inc.

MacDougall, C., Harpe, S. E., Powell, J. P., Johnson, C. K., Edmond, M. B. \& Polk, R. E. (2005). Pseudomonas aeruginosa, Staphylococcus aureus, and Fluoroquinolone use. Emerging Infectious Diseases; 11; 1197-1204.

Mitscher, L. A. (2005). Bacterial Topoisomerase Inhibitors: Quinolone and Pyridine Antibacterial Agents. Chemical Reviews; 105; 559-592.

Mizunaga, S., Kamiyama, T., Fukuda, Y., Takahata, M. \& Mitsuyama, J. (2005). Influence of Inoculum Size of Staphylococcus aureus and Pseudomonas aeruginosa on in Vitro Activities and in Vivo Efficacy of Fluoroquinolones and Carbapenems. Journal of Antimicrobial Chemotherapy; 56; 91-96.

Montanari, M. P., Mingoia, M., Marchetti, F. \& Varaldo, P. E. (1999). In Vitro Activity of Levofloxacin against Gram Positive Bacteria. Chemotherapy; 45; 411-417.

Muramatsu, H., Horii, T., Takeshita, A., Hashimoto, H. \& Maekawa, M. (2005). Characterization of Fluoroquinolone and Carbapenem Susceptibilities in Clinical Isolates of Levofloxacin-resistant Pseudomonas aeruginosa. Chemother; 51; 70-75.

Nester, E. W., Roberts, C. E., McCarthy, B. J. \& Pearsall, N. N. (1973). Molecules, Microbes, and Man. New York: Holt-Reinhart Winston.

Ostle, B. \& Mensing, R. W. (1975). Statistics in Research (3rd ed). Iowa: The Iowa State University Press.

Steel, R. G. D. \& Torrie, J. H. (1981). Principles and Procedures of Statistics: A Biometrical Approach (2nd ed). Auckland: McGraw-Hill Inc.

Yao, J. D. C. \& Moellering, J. R. (2003). Manual of Clinical Microbiology (8th ed). Washington, DC: ASM Press. 